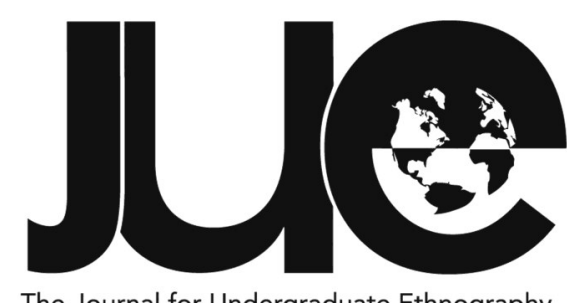

The Journal for Undergraduate Ethnography

\title{
Gendering the Boy Scouts: Examining Hegemonic Masculinity at a Co-Ed Backpacking Camp
}

Samantha Pentecost

Southwestern University, pentecos@alumni.southwestern.edu

\section{ABSTRACT}

Masculinity has been studied in various outdoor settings, including the industries of ecotourism, outdoor education, and forestry. However, few studies have examined how physical space contributes to the construction of hegemonic masculinity in organizations associated with nature and the outdoors. This study relies on nine in-depth interviews conducted with outdoor educators and sixteen hours of ethnographic research completed at Mountain View Scout Camp, a backpacking program for youth operated by the Boy Scouts of America. Findings indicate that Mountain View is gendered both through its organizational aesthetics, which valorize a hegemonically masculine ideal, and via staff members' conception of nature as feminine and forestry work and tools as masculine. Results also suggest that men employed at Mountain View will occasionally embody a hybrid masculine gender performance by utilizing non-hegemonic traits of masculinity such as pro-feminist ideas. However, these episodic masculine performances also serve to subtly reproduce gender inequalities by accepting only a specific type of woman and rewarding men for superficial allyship. 
- he wilderness is gone, the buckskin man is gone, the painted Indian has hit the trail over the Great Divide, the hardships and privations of pioneer life which did so much to develop sterling manhood are now but a legend in history, and we must depend upon the Boy Scout movement to produce the MEN of the future (Daniel Carter Beard, 1910 in Segal 1996:639).

The outdoors, nature, or, as Daniel Carter Beard, one of the founders of the Boy Scouts of America writes, the wilderness, has long been viewed as a perfect place for boys and men alike to challenge themselves and, in doing so, construct their masculine identity. Few organizations have centered nature in their ethos as explicitly and dutifully as the Boy Scouts of America ${ }^{1}$ (BSA), which, from its inception, has considered the outdoors to be the premier place for a boy to become a man (Hantover 1978; Jordan 2016). In part, because of the BSA's long history as a single-gender organization, many Americans were at least mildly surprised to learn that on February $1^{\text {st }}$ of 2019, the Boy Scouts would begin to allow girls into their ranks, integrating one of the largest single-gender organizations in the country.

Although previous research has detailed the relationship between the BSA and masculinity in its nascent stages (Hantover 1978; MacLeod 1982; Jordan 2016), the organization's recent integration necessitates a re-examination of its relationship with gender.

The purpose of this research is two-fold. First, it seeks to provide an estimation of the potential barriers that young women may face in a newly gender integrated Boy Scouts of America. Second, it offers new understandings of how the gendering of space can affect outdoor education, ecotourism, and forestry focused organizations. To accomplish these goals, I examine Mountain View Scout Camp ${ }^{2}-$ one of the BSA's biggest and most profitable high adventure camps which draws thousands of participants from across the country and around the world every summer. Mountain View's operations include both outdoor education and conservation programs, allowing for the study of gender in the industries of outdoor education, ecotourism, and forestry. Mountain View is also a site for examining potential problems elicited by gender integration as it has been co-ed since the 1970s. This history, combined with the fact that it is a major conduit of the BSA's policies, make it an ideal space to examine how the BSA deals with gender and its performance, and how this will potentially affect the young girls and women entering into its programs.

Relying on theories of gendered organizations and multiple theories of masculinity, I consider how hegemonic masculinity is reproduced in the material and spatial context of the organization as well as how individual staff members utilize a hybrid masculinity.

\section{Literature Review: Gendered Spaces and Masculinity}

I draw on two central bodies of literature: the gendering of space and the cultivation of hegemonic and hybrid masculinities. The first section examines the production and gendering of space, specifically organizations, and nature, while the second explores how hegemonic and hybrid masculinities are created and maintained through social interactions and gendered discourses.

\section{Feminine Nature, Masculine Occupations, and the Gendering of Space}

The sociological study of space suggests that it is both processual and relational rather than static, and that space develops over time and through various channels (Löw 2016). Scholars have also discussed how space is both itself gendered and part of the social production of gender (Spain 1992; Colomina 1996; Löw 2006; Wasserman and Frenkel 2015). For this paper, I examine organizations and nature as gendered spaces. 
Joan Acker (1990) pioneered theory arguing that rather than being neutral units that house gendered bodies, organizations should be understood as fundamentally gendered themselves. More recent scholarship has expanded upon Acker's work and has generally followed one of three arguments: 1) bureaucracies are inherently gendered, 2) organizations are gendered if their workforce is dominated by one gender, or 3) organizations are gendered through discourses (Britton 2000). In her "gendering-through-discourse" perspective, Britton (2000) asserted that future studies should examine both the gendered social-historical context of organizations and the ways that actors within these spaces engage in gendered practices. Additionally, sociologists have argued that workplace gender inequalities can be the result of the interplay between the gendered structure of an organization and the gender performance of the workers (Pierce 1995; Williams 1995). For example, Christine Williams (1995) found that men in feminized occupations such as nursing actively seek to differentiate themselves from their female colleagues, and that by doing so, they help to reproduce hegemonic dominance. Also, Jennifer Pierce (1995) discovered that women in the male dominated occupation of trial attorney feel pressured to act more like men in order to be successful at their jobs.

Furthermore, organization members' relationship to their surrounding material space is potentially essential to understanding the less obvious ways that hierarchies and specific gendered identities are created within organizations (Wasserman and Frenkel 2015). Through the study of organizational aesthetics $(\mathrm{OA})$, recent scholarship has addressed the more subtle ways that groups are gendered. OA has been described as "a sensory map through which organizations' members and visitors intuitively sense what the organization is all about, what its main values are, and who the organization sees as the ideal worker (Wasserman and Frenkel 2011, 503). OA can include things such as images that reflect organizational values (Hancock 2005) and art, which can provide information about the historical context of an institution (Strati 1992). All organizations have some type of organizational aesthetics. Relying on and extending these previous studies, I examine the ways that the gendered organizational aesthetics of Mountain View reinforce hegemonic masculinity via the artwork that is commissioned for and prominently displayed at the site.

Although organizational sociology generally calls to mind the traditional office, jobs in more natural settings such as work within ecotourism and forestry industries have also been studied. Ecotourism can generally be understood as a form of tourism based in nature, with key goals such as citizen education, promoting conservation, sustainability, and ethical/ responsible engagement with the outdoors and its resources (Donohoe and Needham 2006). The ecotourism job of "guiding" has been identified as being male-dominated (Tran and Walter 2014), and backpacking and mountaineering, subsections of ecotourism, have traditionally been considered maleoriented recreational activities (Noy 2007; Humberstone 2000; Lugg 2003). In Mendoza's (2020) study of one popular destination in the Patagonian Andes, he found that "ecotourism distinguishes, elevates and valorises certain bodies over others within its logic of accumulation", elevating men whom he identifies as having "alpine masculinity" over women and other men without such a gender identity (211).

The forestry industry has also historically been associated with men and masculinity (Quam-Wickham 1999; Follo 2002; Brandth and Haugen 2005). In the industry itself, domination over nature (Brandth and Haugen 2005), the use of tools (Brandth and Haugen 2005; Desmond 2007), and technical skill (QuamWickham 1999; Desmond 2007) are all ways in which masculinity and manliness have historically been quantified. Matthew Desmond's (2007) ethnography of wildland firefighters in the US Forest Service has revealed how the forest can function not only as a worksite, but also as a place for men to create and enact a certain type of what he calls "country masculinity."

Although many ecotourism and forestry occupations have been closely associated with masculinity, the natural world itself has often been perceived as being more closely aligned 
with femininity. Little and Panelli (2003) have argued that nature "is equated with femininity and with emotions, and set in binary opposition to masculinity, science and rationality" (286). Male dominance over nature has also been documented as being essential to the construction of masculinity in specific local contexts (Woodward 2000). These studies indicate that the natural world is conceived of as a feminine space over which men exert their dominance. However, specific outdoor spaces and areas in nature have also been gendered as masculine ones in an attempt to actively exclude women. Reidy (2015) has recounted how, in an effort to prevent women from having access to European peaks and mountains such as the Swiss Alps, 1800s physiologists crafted elevation zones that they gendered, wherein lower elevations were labeled as feminine and available to women and children, while higher elevations were labeled as masculine and exclusive to men. Morin, Longhurst, and Johnston (2001) have explored a similar phenomenon in more recent times, documenting how women's completion of a difficult mountaineering feat "feminizes" it and lowers its perceived difficulty to other male climbers. With these studies as a backdrop, I explore the ways that gender plays out at Mountain View as an organization, in the interactions among staff members and adult participants, and in the natural landscape in which it resides.

\section{Hegemonic Masculinity and Hybrid \\ Masculinity}

In sociology and many other disciplines, it is widely regarded that gender is something that people "do" and "perform" (Butler 1987; West and Zimmerman 1987). One vein of this scholarship has specifically explored masculinity, how it is performed vis a vis other genders, and the consequences of such performances. Preeminent among this theorizing is Raewyn Connell's (1995) conception of hegemonic masculinity, a form of masculinity that situates the men embodying it into a dominant position over women and, because so few men fully meet its stringent requirements, the majority of other men. Hegemonic masculinity has been identified as having locally, regionally, and potentially even globally specific characteristics that identify a man embodying it (Connell and Messerschmidt 2005). As hegemonic masculinity is not static and represents "the currently most honored way of being a man" (Connell and Messerschmidt 2005, 832), in the United States a hegemonically masculine man is generally understood as being white, economically privileged, cisgender, heterosexual, and able bodied. Scholars in outdoor education studies, ecotourism studies, and rural studies have identified variations of hegemonic masculinity in occupations such as outdoor education (Humberstone 2000), nature guiding (Mendoza 2020), and forestry (Brandth and Hauge 2005).

Although hegemonic masculinity has been sociology's dominant understanding of the hierarchies of gender power, seemingly new forms of masculinity have recently been identified. Bridges and Pascoe (2014) have found that these documented shifts in men's gender performance do not actually represent a change in gendered power structures, but rather are ways of concealing masculinity's privileges through what they call a hybrid masculinity. Men, generally young, white, heterosexual, and affluent, will take on certain traits associated with femininities (Bridges 2010; Arxer 2011; Schmitz and Haltom 2017) or gay (Heasley 2005) or black (Ward 2008; Hughey 2012) masculinities, giving the appearance of having a "better" or "gentler" form of masculinity. Yet, such performances often serve to subtly realign these men with dominant power systems. By doing so, Bridges and Pascoe (2014) have argued that "hybrid masculinities work to fortify symbolic and social boundaries between (racial, gender, sexual) groups - further entrenching, and often concealing, inequality in new ways" (250).

One way that hybrid masculinity can appear more progressive while actually reinforcing social inequalities is through what scholars have identified as discursive distancing (Wilkins 2009; Bridges 2010; Weber 2012; Pascoe and Hollander 2015; Pfaffendorf 2017). Here, men may assume more stereotypical feminine qualities, such as talking openly about their feelings, and in doing so, realign themselves with hegemonic masculine privileges that ultimately benefit them. Potential benefits of using a hybrid masculinity include: attracting women (Wilkins 2009), dominance over other, 
"lesser" men through their demonization (Weber 2012; Pascoe and Hollander 2015; Pfaffendorf 2017), and subtly preserving gender and sexual boundaries (Bridges 2010). In contrast to the largely hollow allyship of hybrid masculinity, Delay and Dyment (2003) suggest that real strides towards equality in industries such as outdoor education can be accomplished by men using their masculine privileges to engage in discussions about and ultimately dismantle structural sexism and exclusion.

There are several gaps in masculinities literature that this study aims to address. First, as an organization associated with the masculine industries of ecotourism, forestry, and outdoor education, Mountain View is a unique space for exploring how hegemonic masculinity is embedded into physical space through organizational aesthetics and members' discourses. Second, research on outdoor educators has done little to examine the specific ways in which hegemonic masculinity is reproduced, and scholarship on outdoor professions and masculinity has primarily been focused on research sites outside of the United States. Furthermore, although prior scholarship has illuminated various ways that space can both inform gendered hierarchies and how these same hierarchies are reflected in space, outdoorfocused industries have remained mostly unexplored through this lens. Finally, there have been no recent sociological studies that have examined gender performance in members of the Boy Scouts of America.

\section{Methodology}

This study relies on nine in-depth, semistructured interviews conducted from April to October of 2018 with outdoor educators at Mountain View Scout Camp as well as ethnographic data from fieldwork conducted during July and August of 2018. Interviewees were recruited through my contacts from Mountain View as well as from a Guide department employee database. Seven individuals were directly asked to participate, while the final two were randomly selected from a pool that expressed interest after I sent a recruitment statement to all the Guides who met specific requirements. I only contacted individuals who were in their second, third, or fourth year as a Guide to ensure that they could answer in-depth questions about working with adult and youth BSA participants. Interviews ranged from 1 hour to 2 hours and 42 minutes, for an average of 1 hour and 25 minutes. Eight of the nine interviews were conducted over the phone, and the final one consisted of a face-toface interview. All individuals were assigned a pseudonym of their choosing prior to beginning their interview.

All interviews were digitally recorded and transcribed. Respondents were asked a series of questions about their experiences with the Boy Scouts of America as well as their work responsibilities and interactions at Mountain View Scout Camp. Phone interviews were necessary for this study because a natural disaster occurred in the summer of 2018 that prevented Mountain View from operating normally and caused many individuals to end their contracts early. Instead of conducting inperson interviews like I had planned, I was compelled to do phone interviews. Therefore, there is at least one limitation to note: phone interviews prevented me from being able to see facial expressions and body language, important cues that are detected with in-person interviews.

All respondents identified as white and were either twenty-one or twenty-two at the time of their interviews. Each had worked at the research site for a minimum of two years, and all were enrolled in some form of higher education most of the year, therefore considering Mountain View to be seasonal employment. Respondents had various levels of affiliation with the Boy Scouts of America; some had grown up in the program since they were very young and others had never been a part of the organization until they decided to work at Mountain View. I interviewed four women and five men. All had been exclusively employed in the Guide department, which hires young adults to teach youth participants and their adult advisors the necessary skills to be able to complete a ten-day, strenuous backcountry trek.

Ethnographic fieldwork was conducted over eight total workdays at the end of the summer of 2018 after a natural disaster disrupted 
Mountain View's normal operations for the season. This event meant that it was difficult to find a stable working schedule until the end of the summer when I served as one of two supervisors for a BSA sponsored forestry team at Mountain View. During the day, my team and I would often work individually but would come together during meals, breaks, and after our shift was over. For this reason, the majority of my notes took place during breaks and after the workday was complete. Every evening, I would write up a summary of the day's events, paying particular attention to comments, actions, and occurrences that were gendered or involving topics concerning gender, sex, or sexuality. These notes were later typed up and coded for themes pertaining to the gendering of the environment and various expressions of masculinity.

As an individual who has been employed by the BSA at Mountain View for four summer seasons, I had easy access to the research site and possessed technical knowledge of the various requirements, culture, and traditions of the organization, allowing me to establish rapport with my respondents quickly. While my positionality as a woman helped me to engage with other women about the hardships of working in a male-dominated and highly masculine space, there is the possibility that male interviewees may have been less open about their opinions concerning gender. Nevertheless, my history of employment and knowledge of Mountain View's inner workings still allowed me to cultivate a sense of trust with male respondents.

As an ethnographer, I was able to easily engage with and observe participants as my own demographic characteristics, being a white individual in my early twenties, match those of the large majority of Mountain View's staff members. I was the only woman in the forestry crew I co-supervised, but this was unusual for the nineteen forestry and fire rehab crews that were in operation during the summer of 2018. Most had at least two women and many had more. My gender was rarely openly commented on by crew members with perhaps the exception of an occasional joke referring to me as a maternal figure. Crew members did not appear to censor themselves around me any more than they did my co-supervisor, meaning that I was privy to all types of interactions including sexually explicit comments and jokes made throughout the day.

\section{The Boy Scouts of America: A Brief History}

The Boy Scouts of America has long been a prosocial organization designed for America's male youth. Sociologists and historians have pointed to various reasons for its rise in prominence in the twenties, including the perceived feminization of middle-class white boys (Hantover 1978), as well as adult Americans' and parents' bid for control over adolescents, whom they perceived as being overly rebellious towards authority (MacLeod 1982). Founded in 1910, the BSA today is one of the most well-known youth organizations in America, eclipsed only perhaps by the YMCA. In its heyday in the 1970s, the BSA's enrollment peaked at approximately 6.3 million active members (Arneil 2010). Today, it has approximately 2.2 million youth participants and 800,000 adult leaders (BSA 2020). Over the last century of its existence, the BSA has had over 110 million members registered within its ranks (Jordan 2016). The BSA's recent drop in participation has been attributed to the organization's inability to shift with changing times and its history of excluding gay and transgender youth and adult participants (Arneil 2010).

While the YMCA and other organizations sought to assimilate immigrant boys into the dominant Protestant culture of the United States, the Boy Scouts of America was founded with the purpose of educating and molding elite, white, male youths (Jordan 2016). Historically essential to the Boy Scouts' ethos is its focus on certain moral values as well as its emphasis on building young men into wellprepared citizens and leaders through training in the outdoors (Hantover 1978; Jordan 2016). Currently, the Boy Scouts describe their mission as being "to prepare young people to make ethical and moral choices over their lifetimes by instilling in them the values of the Scout Oath and Scout Law" (BSA 2020, n.p.). The Boy Scouts of America as an umbrella organization hosts a number of different programs, all of which incorporate community building, interest 
development for youth, and outdoor adventure into their various curricula. These programs include Cub Scouts, Venturing, Sea Scouts, Exploring, and formerly, the Boy Scouts, which today is called Scouts BSA. Of these, Cub Scouts and Boy Scouts were exclusively for male youth up until February of 2019.

As part of their goal of developing young leaders through the outdoors, the BSA operates regional summer camps and larger high adventure bases where Scouts can practice the various leadership and technical skills they have learned, such as knot tying, wilderness survival, and cooking over a fire. At the research site, youth participants and their adult advisors who are generally their parents, guardians, or trusted BSA volunteers, are led by outdoor educators known as Guides. The first women Guides began to work in the 1970s and have since grown as a percentage of the outdoor educators on staff, generally staying a little below a fifth of the department's total members. As of the 2018 summer season, women Guides made up approximately $17 \%$ of the department as a whole and about $26 \%$ of the Guide department's leadership.

\section{Findings}

In the following sections, I explore how hegemonic masculinity is embedded in the physical space of the research site and is a central part of the interactions of camp participants and employees. I argue that the organizational aesthetics of Mountain View and the ways that the institution and employees conceive of nature are informed by and, in turn, reproduce hegemonic masculinity. In the second section, I examine the ways that employees and adult participants utilize various gendered discourses that contribute to the production of both hegemonic and hybrid masculine performances.

\section{The Gendering of Organizational Spaces,} Nature, and Tools at Mountain View

Located at the foot of a large mountain range, Mountain View Scout Camp backs against a long ridge, facing out towards flat plainlands. When Scouts first arrive, either by bus or personal vehicle, they the drive up a narrow two-lane highway, eventually passing under a large sign welcoming them to the camp. After being checked in by staff, they will be introduced to their Guide, a young man or woman who will be with them for the next four days, helping them train and prepare for their ten-day trek in the woods. After introducing themselves, Guides will take crews to drop their gear and luggage off at the small, canvas platform tents they have been assigned for the night. They will then lead them to registration, a trip planning meeting, gear and food pick-ups, a health physical, all of their meals, a chapel service, and finally a nighttime program in which the history and lore of the surrounding landscape and Mountain View is acted out. After camping and hiking with them for their first two nights, instructing them in concepts including wilderness ethics and in skills such as how to set up camp, read maps, and protect their food from bears, Guides will leave crews to complete their trek on their own.

When Scouts and their adult leaders are led across basecamp, they will encounter two pieces of art-a sculpture and a large painting-that set the tone for their upcoming outdoor adventure. While Mountain View has a museum in which many symbols of the camp and the BSA are on exhibit, here I focus on two pieces which are visible to Scouts and their adult leaders within their first half-hour of arriving at camp.

Walking from the welcome center into the main entrance of Mountain View's headquarters, crews pass by a bronze statue entitled "Journey to Manhood." Approximately seven feet tall with a two-foot-high base, the sculpture depicts a young, white Boy Scout dressed in a traditional scouting uniform with a wide-brimmed hat, handkerchief around his neck, high socks, and boots. He appears to be in the middle of a hike as he is carrying a knapsack on his back and a tall walking stick in his right hand. His left foot is placed upon a rock in front of him as he looks towards the southwest, into the plains in front of him.

After passing this statue, the adult leaders of crews will walk into Mountain View's registration office with their Guide. Inside, on the wall that crews face as they check-in, is a portrait of a staff member. The staff member is a young, physically fit white man who is sitting on a stool looking off towards his left. In his 
hand is a map of Mountain View's property. He is wearing brown hiking boots with red laces, which are untied. A hiking backpack with a patch from the Guide department stitched onto it rests against the left side of the stool. In the background is a skyline featuring one of Mountain View's most prominent landmarks.

What is notable about both of these works is that they depict images of young, white, ablebodied men in the outdoors, and both are visible to participants when they first arrive at Mountain View. Also noteworthy is the fact that both images have been used on postcards sold in the camp gift shop and on promotional materials. The latter piece has also been featured on the cover of a book about the Guide department. Conspicuously, there are no visual representations of women in these spaces. While this lack of representation may at first seem self-evident-it is, after all, a Boy Scout camp-it is important to remember that women have been working at the research site for over forty years. These artworks are significant because they demarcate who is foregrounded at Mountain View and who is not.

These visuals are essential to consider because they embody the gendered nature of Mountain View. Similar to Strati's (1992) findings about art in workplaces, both pieces reflect Mountain View's historical and present context. Specifically, it is an organization that caters to young, white, able-bodied, male participants, and where the majority of the workforce has similar demographics. These images' effects on Mountain View's target audience are discussed by Eric, who has worked at the camp for two years. When talking about Scouts' expectations of their trip to Mountain View, Eric said: "If you think about the Guide painting...with his map and everything...like that's the perfect stereotype of like what you would expect [your Guide] to be. Tall, lean guy. White dude. So then if like, you do have a female Guide it just maybe skews [how you envisioned Mountain View] a little bit." Here, Eric noted the power of imagery and how it informs crews' perceptions of who will be leading their trek and who will not. In this case, crews valorize a certain type of masculinity in their leaders: a Scout who is young, strong, white, and a man. This image of masculinity is pervasive within Mountain View's physical setting and marketing images, and the effects of the imagery and the masculinity it depicts are clear: every single woman respondent relayed to me a story in which their position as a Guide was questioned by their crews. For instance, Abigail, a Guide with four years of experience, reported being told, "I didn't know girls could be Guides," and asked, "Girls can work at Mountain View?" Similarly, Rosie recalled, "I had a couple of crews that were like 'Oh, a female Guide, I wasn't expecting that.' So, it definitely was made...known that they were...surprised to get a female Guide."

Many of the women reported jarring feelings of being forced to realize they were thought of as "female Guides" rather than just Guides. This othering commentary was draining for women employees, who expressed frustration that their existence as Guides was regarded with such consistent surprise. Statements and questions like these highlight a disconnect between the actual gender makeup of Mountain View's Guides and the expectations that Scouts have. This confusion can be partially explained by the organization's aesthetics and by which type of people are highlighted and which are left out. Women Guides' visual representation at Mountain View-both virtually on the website and in the physical space-is almost non-existent, a fact that is concerning since women have been working as Guides at Mountain View for decades. The fact that organizationally supported images and art have such a large effect on the perceptions and understandings of Mountain View's participants not only is supported by previous scholarship (Strati 1992; Hancock 2005; Wasserman and Frenkel 2011), but also reveals how Mountain View institutionalizes a locally specific hegemonic masculinity. As Connell and Messerschmidt (2005) note, "at the local level, hegemonic patterns of masculinity are embedded in specific social environments, such as formal organizations" (839). At Mountain View these patterns are embedded visually in the organization's choices in art.

The hegemonic ideal touted by Mountain View also affects male Guides. Bob, a man with two years of experience, described how he has had crews question his ability to do his job because of their perception of his physical fitness, saying, "I've definitely been like looked 
at from some of the adults being like, 'Well this guy is like heavier than me. He's leading us?"' Bob's comment reveals how images that only represent one type of person are hurtful not only to women but also to other men as well.

An analysis of Mountain View's organizational aesthetics reveals that its participants and employees are subtly presented with a visual reminder of who is "supposed" to work there, especially as a Guide. By valorizing a hegemonic male ideal via artwork that Scouts will see when they first arrive at Mountain View, the organization underpins participants' inaccurate perceptions of what a staff member looks like, failing to acknowledge not only women's presence but also the various body types and backgrounds of male employees.

While Mountain View's art contributes to its gendered nature, so does the way that the surrounding landscape is conceived of by its staff. Following a wildfire in the summer of 2018, the majority of staff members, including Guides, were unable to perform the jobs they were originally hired for after Mountain View closed its backpacking programs for the summer. In lieu of their previous assignments, a small portion of the staff members chose to stay and work as part of forestry teams known as Timber Stand Improvement (TSI) crews.

My field research from time spent working as one of two supervisors of an otherwise all-male forestry crew at Mountain View in July and August of 2018 reveals numerous ways that this workplace was gendered. First, I noted that nature was perceived as feminine. Over eight days, I observed numerous instances where members of the conservation crew I was working with referred to mountains and trees as "she" and "her." Comments included excited rallying cries such as "let's go get her" at the start of a work period to more casually referring to the landscape as a whole as a "she." Specific aspects of the surrounding landscape were also sexualized, including a large rock formation named after a woman's breasts and a landmark near Mountain View's basecamp referred to jokingly as "pussy mesa." These comments and the names given to natural geographical features are illustrative of a common finding that historically in Western countries, nature is gendered as feminine (Quam-Wickham 1999; Woodward 2000; Little and Panelli 2003).

In opposition to the feminine landscape, I found that at Mountain View, similar to previous research, forestry work is coded as masculine. Specifically, I found that the use of tools such as handsaws, picmatics, and chainsaws was related to men's constructions of masculinity in the workplace. As Brandth and Haugen (2005) note, in forestry "being capable operators of the machines establishes men's connection to other men and confirm their distance from women" (152). This finding is apparent in my fieldnotes in what I identified as a masculine hierarchy of tools amongst my TSI team. Hand tools such as loppers (sharp clippers for smaller branches) and handsaws of various sizes were viewed as less useful than chainsaws, which were seen as more powerful and ultimately more manly. In my crew, myself and two of the men I supervised had been trained as sawyers and equipped with chainsaws. The tool's connection to masculinity was illuminated by my crew members' continuous commentary on who did and did not have access to a chainsaw and their apparent fascination with operating one. Men who had the training and ability to run a chainsaw were often deemed "cooler," more capable, and ultimately more masculine men. Desmond (2007) similarly notes the importance of the chainsaw to his subjects' masculine constructions, describing how chainsaws were so important to his crew members' gender performance that one competition over who was better at operating a saw almost led to a physical altercation.

Crew members would regularly make comments and jokes indicating that the individuals who used a chainsaw (be they men or women) had larger male genitalia and were more masculine than the men who did not operate one. Although jokes about chainsaws making their operators more "manly" were made in a light-hearted manner, two of the men whom I supervised took a chainsaw and safety gear during a break and posed, pretending to operate the tool, for pictures that they later posted to various social media sites. This posturing indicates that the appearance of having operated a chainsaw represented an opportunity for these men to accrue social clout 
outside of the research site, suggesting that the conception of the tool as being related to masculinity is recognized even outside of a forestry context.

The idea of masculinity being based in having access to and control over naturemodifying tools reflects what Brandth and Haugen (2005) identify as the "macho" man in past eras of Norway's forestry industry. Because the chainsaw is symbolic of being able to perform work and cut down more trees, men who use one are perceived as more productive workers, more dominant over nature, and therefore dominant over others who do not have chainsaws.

Another way that men's interactions with chainsaws served to gender the surrounding environment was when they would compare their chainsaws to a phallus, referring to it as their "chainsaw dick." This reference would often be accompanied by placing the chainsaw between their legs and using it to make sexually suggestive motions while revving it loudly. One man informed me that when he was learning to use the chainsaw, his instructor told him to think of his chainsaw as an extension of his penis in order to help him operate it more effectively. By depicting the chainsaw as a penis, the instructor compared the cutting down of trees to a sex act that requires skill and explicitly implicates a male sex organ in controlling the surrounding physical landscape. The likening of the chainsaw to a phallus constructs it as something that is outside of women's reach. Acker (1990) finds that in gendered organizations "symbolic expressions of male dominance also act as significant controls over women in work organizations because they are per se excluded from the informal bonding men produce with the "body talk' of sex and sports" (153). This understanding would suggest that the chainsaw -as-a-phallus discourse serves to symbolically otherize women, excluding them from certain jokes and camaraderie that men derive from working with the tool.

Just as Desmond (2007) found that the pine forests of Arizona were "a specific and salient outlet for the reproduction, reaffirmation, and reconstitution of the country-masculine habitus" (266), it is clear that Mountain View's backcountry is a space for young men to enact their own carefully crafted form of masculinity via the use of landscape shaping tools. Especially in the Boy Scouts, the ability to master nature in an unsentimental manner was crucial in the measure of a man (Jordan 2016). It is therefore unsurprising that in Mountain View's context, where the natural world is feminized and nature scaping tools are made phallic, that the primary outcome is a space in which hegemonic masculinity is championed.

\section{Hybrid Masculine Performances in Staff Members and Adult Participants}

As noted by previous scholars, the most likely individuals to employ hybrid masculinities are young, straight, middle-class, white men (Bridges and Pascoe 2014). As this fits the demographics of the majority of Mountain View's staff and participants, Mountain View is an ideal location to examine if men in outdoor industries embody hybrid masculinity.

Interviews with staff members indicated that men at Mountain View, both adult participants and staff, employ hybrid masculinity through a number of ways. Bridges and Pascoe (2014) find that hybrid masculinity is characterized by men engaging in the practices of discursive distancing and appropriating characteristics of femininities and subordinate masculinities. While these actions appear to be progressive, they actually lead to the fortification of gendered boundaries and the concealment of social inequalities. I found that men at Mountain View drew on pro-feminist ideas by openly discussing sexism and gender equality while simultaneously labeling other men as the sole possible perpetrators of sexism. In doing both, men constructed themselves as being apart from hegemonic masculinity while still actively benefiting from its privileges.

Hybrid masculine performances are visible in the ways that men discuss and frame having female coworkers in the Guide department. Four out of five male respondents reported that working with women at Mountain View led to them experiencing a turning point related to their beliefs about women's capability as backpackers and leaders. For instance, when discussing his first training trek when he was learning to be a Guide, Jaxon, a man who had worked in the department for four years, noted: 
"I can't stress enough...[how] valuable that experience was because like I knew girls could backpack, I had just never seen it...I couldn't tell you if girls acted differently in the outdoors or not. But then, hiking with them, backpacking with them [l saw] it doesn't matter your gender." While this change in understanding is initially positive, it underscores the conception that women at Mountain View are different and special compared to other women. Jaxon continued his previous thought saying "the girls out here are the cream of the crop...but as far as boys go, you have a whole spectrum of them from those that cry the entire time to those who are a step away from Navy Seals." Jaxon clearly views these women and their abilities in a positive light, but his comments also reveal how gender boundaries are reified as women at Mountain View are painted as always being exceptional while men are allowed more variance in their abilities.

Abigail describes a similar phenomenon among adult male participants when she discussed an instance when an adult advisor that had been to Mountain View before was particularly excited to see her walk up as their Guide. She recalled how he told her that when his sons went to Mountain View, he hoped that they would meet women there because then he would know that "the girlfriends would be awesome and cool and like, strong women." It was for this same reason that he thought that Abigail's presence as a Guide would be constructive for the boys so that they could see what an "outdoorsy" girl looked like and eventually "find [themselves] a girl like [that]." While this adult leader's positive conception of women Guides is not immediately problematic, his framing of female Guides as women who are "cool and strong" implies that other women are not, and further serves to limit these women Guides by treating them as a homogenous group. In doing so, the women are also reduced to being potential marriage material rather than being recognized for their abilities as a leader and educator.

One of the principal ways in which men would engage in discursive distancing was by presenting themselves as individuals who were socially aware and therefore better than other men. Three out of five men I interviewed labeled certain groups of other men as perpetrators of sexist and regressive behavior. The men who were typically identified as being the cause of women's experiences with sexism were older male advisors and crews from parts of the country that are often stereotyped as less progressive. For instance, Eric said, "I'm in the Northeast, and people are a lot different here than say, you know, a middle-aged Scoutmaster from Alabama." Alexander, a Guide with two years of experience also referred to "the crews like from the backwoods of Texas or Alabama" as the ones where "the advisors don't trust [female Guides] as well." Although Mountain View's participants come from all over the United States and even internationally, Eric and Alexander specifically identified adult Boy Scout leaders from the geographic South as the individuals who are sexist. In contrast, Eric described himself as needing to remain "professional" during interactions with such crews, demonstrating a sense of superiority to men with regressive, less socially aware masculinities (Wilkins 2009; Pfaffendorf 2017).

The idea that it is only adult male participants from certain parts of the country that are sexist is directly contradictory to my ethnographic findings and women Guides' stories. For instance, Jackie, a Guide with three years of experience, once had a supervisor make jokes about her staying in the kitchen while her male counterparts were out hiking. By constructing certain "other" men as engaging in sexist practices, these interviewees subtly distanced themselves from hegemonic masculinity's privileges. This distancing is, of course, only symbolic, as each of these men still reaps the benefits that their identity affords them. While recognition of privilege is an important step, it means little if nothing is done to actively help dismantle hegemonic structures. Delay and Dyment (2003) suggest that a counter-hegemonic alternative for men in the outdoor industry would be for them to actively encourage others to both recognize the issue and to use their privilege to prevent it in the future.

By framing themselves as socially aware and different than other men, male Guides are likely to gain significant social approval, especially from women who are used to being in a space that marginalizes them. Eric explained how men 
can leverage public displays of support for women to their own advantage: "If I called out a guy on something, it would probably be seen as a good thing just because there is that macho environment at Mountain View, like the fact that I would directly challenge another guy would probably get me some prestige." This quote helps to illuminate why men might hybridize their masculinities, but also how in doing so they realign themselves with the competitive nature of hegemonic masculinity in attempting to gain "prestige" and social dominance over other men.

These findings are not to suggest that all men engaged in a hybrid performance of masculinity. Indeed, women reported experiences that ranged from open acts of sexism, such as when an adult advisor told Polly, a Guide with four years of experience, "that he didn't respect women's authority," to microaggressions, such as when adult leaders made demeaning comments on one woman's fingernail polish. All of the men I interviewed were also aware of or had personally witnessed a time when a female coworker had experienced sexism at Mountain View. These instances were generally readily and vividly recalled, and male respondents always described them disapprovingly. When asked if he was aware of sexism at Mountain View, Bob recounted how a close friend ran up to him crying. "[Her crew was] blatantly sexist, being like 'Where's our Guide?' and she was like 'Well I am your Guide,' and they're like 'Well can we get a guy one?"' However, despite being aware of instances like the one described above, all male interviewees still reported that overall they considered Mountain View to be a safe place for everyone who came to participate and work. Although several said that participants' and staff's physical safety was not completely guaranteed because of the outdoor setting, they overall agreed that Mountain View was generally a psychologically safe place.

Unlike the men in Pfaffendorfs (2017) study who used hybrid masculinities in the face of a "masculinity crisis," those at Mountain View do not face such a battle as the majority embody traits that would align them with hegemonic masculinity. However, as I have shown, it appears that at times, these men may embody hybrid masculinities as a way to demonstrate to both others and perhaps even to themselves that they are one of "the good guys". Furthermore, while I documented all of the male respondents as viewing women and their abilities in a positive light, it appears that their framing quietly, and perhaps even subconsciously, reaffirms gendered boundaries and inequalities, such as the idea that women at Mountain View are the exception to the rule when it comes to women as a whole.

\section{Discussion and Conclusion}

Relying on interviews with staff members and participant observation at a backpacking camp operated by the Boy Scouts of America, I found that Mountain View Scout Camp functions as a gendered organization in three main ways. First, the prominent pieces of artwork that are placed in Scouts' paths when they first arrive at Mountain View manifest an image of a particular kind of employee that Scouts should expect to encounter at Mountain View. Because of this imagery, participants may expect staff members to be young, white, physically strong, able-bodied men, effectively erasing the existence of women and men who deviate from these characteristics. Second, at the research site, nature is constructed as feminine and forestry work, which alters said landscape, is gendered as masculine. The use of landscapealtering tools such as a chainsaw is framed as only being available to men by associating it with male genitalia. Finally, men will episodically use hybrid masculinities to present themselves as advocates of female Guides, but in doing so, actually reify gender boundaries. By coding women at Mountain View as being different or unique as compared to "other" women, gender inequalities continue to be upheld, especially considering that there was little recognition of the more damaging effects of sexism in regards to women's experience and safety at Mountain View as a whole.

There is a dearth of recent sociological research that has examined the ways that the Boy Scouts of America is gendered. As Acker (1990) and Britton (2000) caution, rather than assuming organizations to be gender neutral, as a sociologist it is crucial to explore the processes that make them so. Because the Boy Scouts of America has recently integrated, the study of Mountain View-an integral program 
in the organization and a space that has been co-ed for over forty years-is a helpful tool in predicting some of the barriers that young women will face as they begin to enter the ranks of one of the nation's oldest and largest single-gender youth programs. Mountain View and other outdoor education and ecotourism programs in the BSA and beyond need to consider the various ways in which their organizations and associated spaces are subtly exclusionary. In reviewing the characteristics that I have outlined in this study, organizations can work to examine whether they are actually welcoming to young women (and to various types of men) or whether they are only so for a singular hegemonic ideal.

My work adds to the literature on gender in outdoor education in two important ways. First, although previous work on masculinity in outdoor education programs has touched on the presence of hegemonic masculinity, my research explicitly reveals how certain spatial characteristics and various gender performances by staff members can reinforce it in a myriad of ways. Secondly, in line with Wilkins (2009) and Pfaffendorf (2017), my study adds to the growing scholarship on hybrid masculinities by finding that some men may embody a seemingly more progressive type of masculinity while distancing themselves from other men who they deem "sexist." This study also finds that some older men, generally in their late thirties to early sixties, can also engage in hybridized masculine practices and discourses, which is particularly notable given that most other studies have focused on young men in their late teens and early twenties.

Future research should more closely examine how whiteness serves to foster hegemonic masculinity within the BSA and its programs. Hybrid masculinity scholars would also be well served to examine how men's identities as Boy Scouts influence whether they choose to embody hybrid masculinity. Men in my study often talked about the influences of the BSA on their identity as a man, and they would describe those in the Boy Scouts as being superior citizens and people, "the cream of the crop" of young men in the United States. These recurring comments may indicate that the BSA has institutionalized a narrative embedded in discursive distancing that separates its members from non-member "others." Such a study could therefore be a way to examine if hybrid masculinity itself is institutionalized.

A potential limitation of this study is that data collection occurred immediately following a natural disaster that disrupted the camp's normal operations. Consequently, I had to rely almost exclusively on phone instead of inperson interviews. Nevertheless, this change in Mountain View's normal operations is the main reason I became a leader of a forestry crew which was a source of rich ethnographic data. Additionally, although some might initially view the homogeneity of my sample (all participants identify as white and heterosexual) as a limitation, these characteristics actually mirror the demographics of the BSA and Mountain View. Also, it allowed me to garner crucial insights into how men's hybrid masculine performances can operate even within an organization that openly and continually valorizes a hegemonically masculine ideal.

These findings are significant because they demonstrate how space can be gendered both through material channels and through hybridized gender performances, which uphold existing structures of power. Finally, with the recent integration of women into the BSA, it is vital to identify some of the more subtle barriers that young women will undoubtedly face in this program. Doing so will ideally allow outdoor educators and members of the Scouts to begin the process of working together to ensure that these newly co-ed spaces are ones in which gendered hierarchies are challenged and dismantled. 


\section{Acknowledgements}

I must first thank Dr Maria Lowe for her tireless support of both this article and me throughout my undergraduate career. I am forever grateful for her feedback, countless suggestions, and for consistently pushing me to be a better sociologist and student. I am also indebted to Madeline Carrola and Veronica Ciotti for their many edits, but especially for their friendship and camaraderie throughout the oftentimes grueling process of transcribing, writing, and editing. Finally, I owe thanks to my respondents for sharing their stories, and to the friends, professors, and family members who have supported me and my research.

\section{Endnotes}

${ }^{1}$ As of February 1, 2019, the Boy Scouts of America officially changed the name of its flagship program from Boy Scouts to Scouts BSA in an effort to reflect its newly gender integrated status. I refer to the Scouts BSA program by its former title of Boy Scouts to reflect the time during which I completed my research. The national organization remains the Boy Scouts of America or BSA to this day.

${ }^{2}$ This name is a pseudonym for my research site as per my agreement with its higher leadership.

${ }^{3}$ In an effort to mask the identity of my research site, this name is a pseudonym which captures the general spirit of the original title. 


\section{References}

Acker, Joan. 1990. “Hierarchies, Jobs, Bodies: A Theory of Gendered Organizations." Gender \& Society 4(2): 139-158.

Arneil, Barbara. 2010. "Gender, Diversity, and Organizational Change: The Boy Scouts vs. Girl Scouts of America." Perspectives on Politics 8(1): 53-68.

Arxer, Steven L. 2011. “Hybrid Masculine Power: Reconceptualizing the Relationship Between Homosociality and Hegemonic Masculinity." Humanity \& Society 35(4): 390-422.

Boy Scouts of America, 2020. "About the BSA." Irving, Texas: Boy Scouts of America. Retrieved May 3, 2020 (https:// www.scouting.org/about/).

Brandth, Berit, and Marit S. Haugen. 2005. "Text, Body, and Tools: Changing Mediations of Rural Masculinity" Men and Masculinities 8(2): 148-163.

Bridges, Tristan. 2010. “Men Just Weren't Made to Do This: Performances of Drag at 'Walk a Mile in Her Shoes' Marches." Gender \& Society 24(1): 5-30.

Bridges, Tristan, and C. J. Pascoe. 2014. "Hybrid Masculinities: New Directions in the Sociology of Men and Masculinities." Sociology Compass 8(3): 246-258.

Britton, Dana M. 2000. “The Epistemology of the Gendered Organization." Gender \& Society 14(3): 418-434.

Butler, Ruth. 1987. “Task-Involving and Ego-Involving Properties of Evaluation: Effects of Different Feedback Conditions on Motivational Perceptions, Interest, and Performance." Journal of Educational Psychology 79(4): 474-482.

Colomina, Beatriz. 1996. Sexuality \& Space. New York: Princeton Architectural Press.

Connell, Raewyn W. 1995. Masculinities. Berkeley: University of California Press.

Connell, Raewyn W., and James W. Messerschmidt. 2005. "Hegemonic Masculinity: Rethinking the Concept." Gender \& Society 19(6): 829-859.

Delay, Randolph H., and Janet E. Dyment. 2003. "A Toolkit for GenderInclusive Wilderness Leadership." Journal of Physical Education, Recreation \& Dance 74(7): 28-32. 
Desmond, Matthew. 2007. On the Fireline: Living and Dying with Wildland Firefighters. Chicago: University of Chicago Press.

Donohoe, Holly M., and Roger D. Needham. 2006. “Ecotourism: The Evolving Contemporary Definition." Journal of Ecotourism 5(3): 192-210.

Follo, Gro. 2002. "A Hero's Journey: Young Women Among Males in Forestry Education." Journal of Rural Studies 18: 293-306.

Hancock, Philip. 2005. "Uncovering the Semiotic in Organizational Aesthetics." Organization 12(1): 29-50.

Hantover, Jeffrey P. 1978. "The Boy Scouts and the Validation of Masculinity." Journal of Social Issues 34(1): 184-195.

Heasley, Robert. 2005. “Crossing the Borders of Gendered Sexuality: Queer Masculinities of Straight Men." In Thinking Straight: The Power, Promise and Paradox of Heterosexuality, edited by Chrys Ingraham, 109-129. New York: Routledge.

Hughey, Matthew. 2012. White Bound: Nationalists, Antiracists, and the Shared Meanings of Race. Stanford: Stanford University Press.

Humberstone, Barbara. 2000. “The 'Outdoor Industry' as Social and Educational Phenomena: Gender and Outdoor Adventure/ Education." Journal of Adventure Education and Outdoor Learning 1(1): 21-3.

Jordan, Benjamin René. 2016. Modern Manhood and the Boy Scouts of America: Citizenship, Race, and the Environment, 1910-1930. Chapel Hill: University of North Carolina Press.

Little, Jo, and Ruth Panelli. 2003. "Gender Research in Rural Geography." Gender, Place and Culture 10(3): 281-289.

Löw, Martina. 2006. "The Social Construction of Space and Gender." European Journal of Women's Studies 13(2): 119-133.

Löw, Martina. 2016. The Sociology of Space: Materiality, Social Structures, and Action. Translated by Donald Goodwin. New York: Palgrave Macmillan.

Lugg, Alison. 2003. "Women's Experience of Outdoor Education: Still Trying to Be 'One of the Boys'?" In Whose Journeys: The Outdoors and Adventure as Social and Cultural Phenomena, edited by Barbara Humberstone, Heather Brown, and Kaye Richards, 3348. Barrow-in-Furness, UK: Fingerprints. 
MacLeod, David I. 1982. "Act Your Age: Boyhood, Adolescence, and the Rise of the Boy Scouts of America." Journal of Social History 16(2): 3-20.

Mendoza, Marcos. 2020. "Alpine Masculinity: A Gendered Figuration of Capital in the Patagonian Andes." Bulletin of Latin American Research 39(2): 208-222.

Morin, Karen M., Robyn Longhurst, and Lynda Johnston. 2001. "(Troubling) Spaces of Mountains and Men: New Zealand's Mount Cook and Hermitage Lodge." Social \& Cultural Geography 2(2): 117-139.

Noy, Chiam. 2007. "Travelling for Masculinity: The Construction of Bodies/Spaces in Israeli Backpackers' Narratives." In Tourism and Gender: Embodiment, Sensuality and Experience, edited by Annette Pritchard, Nigel Morgan, Irena Ateljevic, and Candice Harris, 47-72. Wallingford, UK: CABI.

Pascoe, C. J., and Jocelyn A. Hollander. 2015. "Good Guys Don't Rape: Gender, Domination, and Mobilizing Rape." Gender \& Society 30 (1): 67-79.

Pfaffendorf, Jessica. 2017. "Sensitive Cowboys." Gender \& Society 31 (2): 197-222.

Pierce, Jennifer L. 1995. Gender Trials: Emotional Lives in Contemporary Law Firms. Berkeley: University of California Press.

Quam-Wickham, Nancy. 1999. “Rereading Man's Conquest of Nature: Skill, Myths, and the Historical Construction of Masculinity in Western Extractive Industries." Men and Masculinities 2(2): 135151.

Reidy, Michael S. 2015. "Mountaineering, Masculinity, and the Male Body in Mid-Victorian Britain." Osiris 30(1): 158-181.

Segal, Eric. 1996. "Norman Rockwell and the Fashioning of American Masculinity" The Art Bulletin (78)4: 633-646.

Schmitz, Rachel M., and Trenton M. Haltom. 2017. "II Wanted to Raise My Hand And Say I'm Not A Feminist': College Men's Use Of Hybrid Masculinities To Negotiate Attachments To Feminism And Gender Studies." The Journal of Men's Studies 25(3): 278-297.

Spain, Daphne. 1992. Gendered Spaces. Chapel Hill: University of North Carolina Press. 
Strati, Antonio. 1992. "Aesthetic Understanding of Organizational Life." The Academy of Management Review 17(3): 568-581.

Tran, Linh, and Pierre Walter. 2014. "Ecotourism, Gender and Development in Northern Vietnam." Annals of Tourism Research 44: 116-130.

Ward, Jane. 2008. "Dude-Sex: White Masculinities and 'Authentic' Heterosexuality Among Dudes Who Have Sex with Dudes." Sexualities 11(4): 414-434.

Wasserman, Varda, and Michal Frenkel. 2011. “Organizational Aesthetics: Caught Between Identity Regulation and Culture Jamming." Organization Science 22(2): 503-521.

Wasserman, Varda, and Michal Frenkel. 2015. "Spatial Work in Between Glass Ceilings and Glass Walls: Gender Class Intersectionality and Organizational Aesthetics." Organization Science 36(11): 1485-1505

Weber, Jennifer. 2012. "Becoming Teen Fathers: Stories of Teen Pregnancy, Responsibility, and Masculinity." Gender \& Society 26 (6): 900-921.

West, Candace, and Don H. Zimmerman. 1987. "Doing Gender." Gender \& Society 1(2): 125-151.

Wilkins, Amy. 2009. "Masculinity Dilemmas: Sexuality and Intimacy Talk among Christians and Goths." Signs 34(2): 343-368.

Williams, Christine L. 1995. Still a Man's World: Men Who Do "Women's" Work. Berkeley: University of California Press.

Woodward, Rachel. 2000. "Warrior Heroes and Little Green Men: Soldiers, Military Training, and the Construction of Rural Masculinities." Rural Sociology65(4): 640-657. 